corresponding figures were seventy-two and eightyfive, respectively, while eight readers visiting the special collections were non-residents of Manchester and three residents. Following the publication of the Manchester Joint Research Council's survey, "Science and Industry", the 225 firms participating in the survey were circularized with a brief statement of the services offered by the technical library, which now holds 86,572 volumes, and a selection of the latest publications. A large proportion of the inquiries received were connected with technical research or development. The number of readers using the library increased by 4,812 to 150,388 , and the number of periodicals consulted increased, although the number of books used decreased slightly. Stress is laid on the importance of co-operation in this field and on the cost of scientific and technical books, which during the year averaged $40 s$. $8 d$. per volume.

\section{Nitrogen Metabolism of Groundnut Plants}

L. Fowden (Ann. Bot., 18, 72, $417 ; 1954$ ), in an investigation of the nitrogen metabolism of Arachis hypogaea, has considered in some detail the role of $\gamma$-methyleneglutamine and $\gamma$-methyleneglutamic acid - two new compounds which are apparently not widely distributed in plants, as are, for example, asparagine and glutamine. The evidence that $\gamma$-methyleneglutamine was not present in ungerminated groundnut seeds and that $\gamma$-methyleneglutamic acid could not be detected in an acid hydrolysate of arachin, the principal reserve protein of groundnut seeds, suggested the possibility that important differences may be encountered between the roles of the new amide in groundnut plants and those of asparagine and glutamine in other species. The changes in various nitrogenous fractions during the growth of groundnut seedlings in the dark were compared with those occurring in seedlings grown in the light. The distribution of amides and acidic amino-acids in the various organs of young and mature plants has also been studied quantitatively, and observations have been made upon the aminoacids present in developing fruits. The author discusses the possible pathways of synthesis and the functions of these two substances in the groundnut plant.

\section{Rayleigh Waves in a Medium with Two Surface Layers}

THE problem of the propagation of waves of Ray. leigh type in a uniform semi-infinite elastic medium with two uniform surface layers has been solved by R. Stoneley, in a paper entitled "Rayleigh Waves in a Medium with Two Surface Layers" (Mon. Not. Roy. Astro. Soc., Geophys. Supp., 6, No. 9, 610; 1954). The waves are dispersive, and the wave velocity equation turns out to be a determinant of the tenth order. Various tests on the equation proved it to be satisfactory: for example, by making infinite the thickness of the surface sheet it is possible to derive the velocity equation for waves in an internal stratum; and by making the thickness of either sheet zero, the known equation for the velocity of Rayleigh waves in a medium with a single surface layer is obtained. If the wave-length is very small, the determinant reduces to the product of three determinants, which, equated in turn to zero, are the velocity equations of very short Rayleigh waves at the free surface and of very short waves of Rayleigh type at the two interfaces. Dr. Stoneley intends to give the results of a numerical solution of the wave equation at a later date, as well as a discussion of the application of the results to the actual surface waves of earthquakes.

\section{"The Rationalist Annual"}

Among the articles contributed to "The Rationalist Annual" for 1955 (pp. 81. London: C. A. Watts and Co., Ltd., 1954. Cloth, 5s.; paper, 2s. 6d.) are the late Sir Arthur Keith's comparison of Darwin and Locke as philosophers, "Darwin's Place among Philosophers". Sir Arthur claimed that if Locke is accepted as a philosopher, Darwin must be regarded as one too, and he added that Darwin was the only philosopher known to him who could help in the interpretation of the problems of nationality and war which vex our modern world. Mrs. Margaret Knight suggests that good and evil, and joy and pain, are reconciled, in the only sense in which their reconciliation is possible, on the rsthetic plane; but her essay seems to touch the experience of the scientist, as such, less than those of Prof. Morris Ginsberg on "Durkheim's Theory of Religion" and Prof. J. B. S. Haldane on "The Origin of Purpose". Prof. V. Gordon Childe writes briefly on "The Stone Age comes to Life", E. H. Hutton on "Religion and the Physicists", Antony Flew on "The Third Maxim", an analysis of the reason J. B. S. Haldane once gave for not being a materialist, Bertram Joseph on "The Renaissance Mind" and Ernest Gellner "On Being Wrong".

\section{Microwave and Radio-frequency Spectroscopy}

THE Faraday Society will hold a General Discussion on "Microwave and Radio-frequency Spectroscopy" in the Department of Zoology, University of Cambridge, during April 4-6. The programme will be in four parts, at each of which a general introduction will be given by the person shown : microwave spectroscopy (Prof. H. C. Longuet-Higgins, University of Cambridge); microwave absorption (Dr. T. M. Sugden, University of Cambridge); nuclear magnetic resonance (Prof. H. S. Gutowsky, University of Illinois) ; and quadrupole spectroscopy (Prof. B. P. Dailey, Columbia University). Twentythree papers will be read, and advance proofs will be circulated about the middle of March. Applications for accommodation must be made by March 23 . Further information can be obtained from the Secretary, Faraday Society, 6 Gray's Inn Square, Gray's Inn, London, W.C.1.

\section{Summer School of Welding}

THE fifth Summer School of Welding organized by the British Welding Research Association will be held at Ashorne Hill, near Leamington Spa, Warwickshire, during June 27-July 2. The School will take for its basic theme "Welding Developments in British Industry", and has been devised to cover various aspects in logical sequence during the course. As in previous years, lectures of general interest will be given in the morning, and lectures of more specialized interest in the afternoon. To meet particular requirements, the course will be divided into the following groups : $A$, pressure vessels ; $B$, trensport ; $C$, shipbuilding; $D$, specialized welding techniques. It is possible that an additional group on "Inspection and Testing" will also be included. Further information can be obtained from the Organizing Secretary, Summer School of Welding, B.W.R.A., 29 Park Crescent, London, W.1. 